\title{
Modeling Current and Future Role of Agricultural Waste in the Production of Bioethanol for Gasoline Vehicles
}

\author{
Shahram Badamchizadeh, Ahmad Jahan Latibari,* Ajang Tajdini, \\ Shademan Pourmousa, and Amir Lashgari
}

This study addressed the urgent need for biofuels even in countries such as Iran, which has fairly good fossil fuel resources. The problems, necessities of the present, and future demand for biofuels are discussed. As the transportation sector is one of the largest sources of air pollution, this study has focused on this sector. This issue was examined from a global perspective, and then within the context of domestic bioethanol production using agricultural residues and proposing different scenarios. The first step in implementing this policy is the accurate forecast of the demand for second-generation bioethanol in the coming years. A nonlinear auto regressive neural network was applied to predict gasoline demand based on Mackey-Glass chaotic time series. Gasoline demand is forecasted by 2030 , based on projected volumes of gasoline in different bioethanol mixture scenarios. Results revealed that using scenarios E10, $\mathrm{E} 15$, E25, the volume of bioethanol needed by 2030 will amount to 10.12 , 15.16 and 25.31 million $L$ per day which can be produced using agricultural products wastes.

Keywords: Agricultural waste; Biofuel; Second generation bioethanol; Forecast model; Gasoline vehicles

Contact information: Department of Wood and Paper Science and Technology, Karaj Branch, Islamic Azad University, Karaj, Iran;

*Corresponding author: Latibari@kiau.ac.ir

\section{INTRODUCTION}

Current air pollution has reached a new record in terms of the number of unhealthy days (Air Quality Control Company 2021). The simultaneous increase in pollution with the reduction in traffic due to the COVID-19 pandemic shows that the problem of metropolises has not been solved by reducing traffic based on previous government policies. Therefore, it is necessary to quickly reconsider the consumption of fossil fuel resources. The solution proposed by environmentalists is to replace some fossil fuels with biofuels (Nikkhah et al. 2020). However, due to the abundance of fossil resources in Iran, this policy has not been implemented. Although Iran is ranked first and fourth in terms of gas and oil resources in the world, respectively (World Energy Council 2016), it still needs to think of biofuels.

These problems are not specific to Iran but are important in other countries in the world as well. According to current statistics, in the first quarter of 2021, approximately 7 billion tons of carbon dioxide were emitted, and 990000 hectares of forests were lost (Worldometers 2021). The same source shows that the world will only have oil for about 42 years. 
Environmental problems including global warming (due to the accumulation of greenhouse gases), global climate change, pollution in metropolitan areas, and the consequent increase in mortality and health problems have become a major problem for human survival (Cohen et al. 2017). The most dangerous consequences of air pollution are increased premature deaths. Air pollution is also closely related to many diseases including heart disease, stroke, chronic obstructive pulmonary disease, acute respiratory infection, lung cancer, neuropsychiatric disorders, etc. (Cohen et al. 2017; Hahad et al. 2020).

Air pollution is not only a threat to human health, but it also reduces life expectancy, and the quality, income, and economic growth of countries by causing disease and premature death (World Bank Group and IHME 2016; Ho et al. 2020; The World Bank 2020). Air pollution imposes long-term and lasting effects in other ways. For example, it hinders the growth of plants, reduces agricultural productivity, and causes financial losses (Gheorghe and Ion 2012).

The benefits of using biofuels include reducing greenhouse gas (GHG) emissions and other socio-economic and political advantages. Biofuels significantly reduce greenhouse gas emissions and the dependence on crude oil, diversify energy, and create a large number of rural jobs (Ahorsu et al. 2018; Alalwan et al. 2019). Furthermore, considerable research is underway to provide biofuels on a larger scale, which are more cost-effective and fully economical for the final consumers (Bonenkamp et al. 2020). This research is directed on effective factors in the cultivation of biological products through soil optimization, fertilizer application (Field et al. 2018), location planning for production at the lowest cost (Mostafaeipour et al. 2020), more efficient supply chain (Rabbani et al. 2020), development and upgrading of biomass pretreatment to reduce production costs on an industrial scale (Hassan et al. 2018; Cheah et al. 2020), and upgrading production technology to produce more and cheaper products (Sarkar et al. 2012; Tursi 2019; Gilani and Sahebi 2020). Of course, the use of other methods such as carbon capture and storage technology also play an important role in helping biofuels to solve these problems (Mikhelkis and Govindarajan 2020; Yanagi and Nakamura 2020). Therefore, if societies desire to solve the problem of climate change while maintaining energy security, they must use renewable energy technology (Department of Energy \& Climate Change 2012). The main role of plants on this planet is photosynthesis and conversion of carbon dioxide to oxygen (Szulecka 2019).

\section{Global Need for Replacement of Fossil Fuels with Biofuels in the Transport Sector}

Based on the latest official statistics published by 2020, the transportation sector, the second-largest energy consumer, consumed $32 \%$ of the total final energy consumption by 2017 (REN21 2020). But this sector has the lowest share of renewable energy consumption (i.e. 3.3\%, of the total final energy consumption, $3 \%$ is from biofuels, and $0.3 \%$ is from renewable electricity). This data shows that the transportation sector continues to depend on fossil fuels (REN21 2020).

The arguments presented above lead us to conclude that environmental issues, diseases, and deaths due to air pollution are mostly attributed to the consumption of fossil fuels in the transportation sector, and policies to reduce fossil fuel consumption should target the transportation sector, especially passenger vehicles. Based on the latest official statistics at the end of 2020, the United States, Brazil, the European Union, ASEAN, China, and India were the world's largest producers of biofuels, respectively, However, the consumption growth is expected to be higher in these regions in 2030 (Fig. 1A). The 
remarkable point is that biofuel consumption in passenger vehicles is expected to be higher than any other transportation sector, by 2030 (Fig. 1B). Meanwhile, some countries such as members of the European Union, intend to reduce fossil fuel consumption in the transport sector (Hamje et al. 2014).

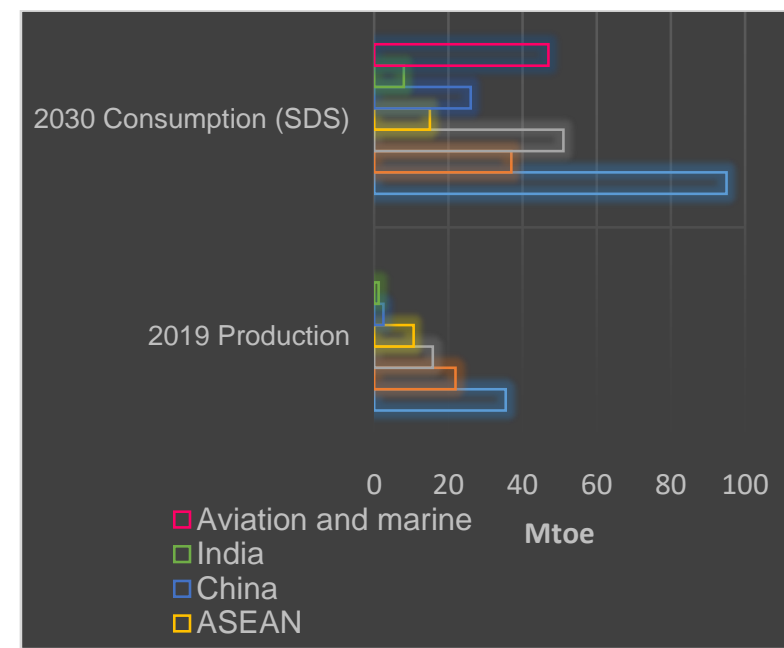

(a)

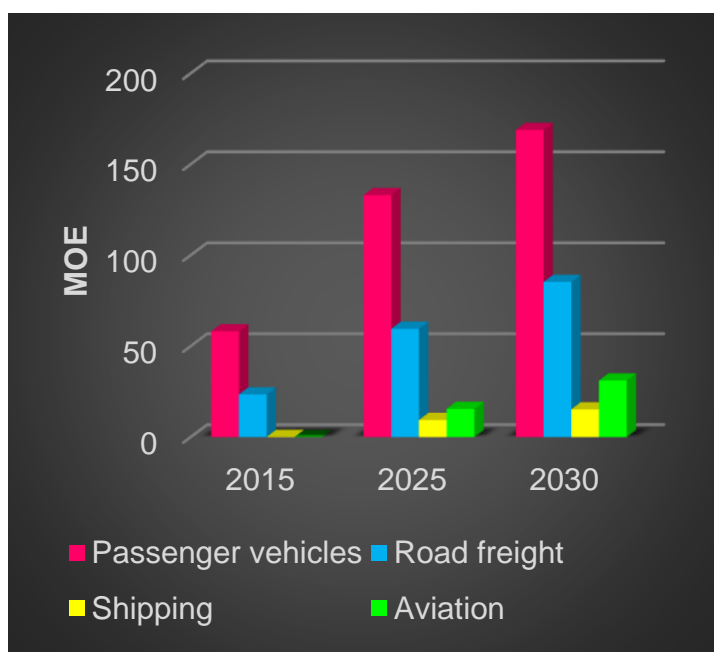

(b)

Fig. 1. Biofuel production in 2019 compared to consumption in 2030 based on the sustainable development scenario of IEA (a), Biofuel consumption breakdown in the sustainable development scenario of IEA 2015-2030 (b) (IEA 2020)

Gasoline is the main fuel for light and passenger vehicles in metropolitan areas, and energy security and environmental issues necessitate that a clean and sustainable alternative to gasoline needs to be introduced. Bioethanol can be used in gasoline vehicles when mixed with fossil fuels up to $30 \%$ without the need for any major changes in vehicle power generation structure (Safarian and Unnthorsson 2018). The combination of these two fuels imparts a significant effect on reducing the generation of pollutant gases by gasoline-burning vehicles (Kazemi Shariat Panahi et al. 2019). Since bioethanol contains higher oxygen atoms in its structure, it increases the efficiency of the engine, even compared with higher octane, and it improves the performance of the engine (Safarian and Unnthorsson 2018). Overcoming environmental problems requires extensive global cooperation. Despite a global consensus to limit greenhouse gas emissions in some countries, the governments have not yet taken the issue seriously. Therefore, the legislation and implementation of emissions regulation and government protection laws for the green fuel sector and its economic incentives are still pending (Farine et al. 2012; Neves et al. 2020). Although the value of biofuels goes beyond their use as transportation fuels, the economic and environmental benefits of biofuels must be considered.

\section{The Necessity to Substitute Gasoline with Bioethanol in Transport Sector in Iran}

Iran and especially its capital are among the worst affected by air pollution in terms of both the estimated number of deaths and financial losses (Heger and Sarraf 2018). Iran is among the top 10 greenhouse gas producing countries in the world and ranks $9^{\text {th }}$ (Environment and Climate Change Canada 2020), and it is the $27^{\text {th }}$ country in the ranking of the most polluted countries in the world (IQAir 2019). Consumption of petroleum 
products, especially gasoline, in Iran has increased sharply due to the increasing population and consequently an increase in the number of gasoline vehicles. An official report issued by the Iran Petroleum Products Refining and Distribution Company shows that in 2017, almost a quarter of all Iranian petroleum products have been consumed in the transportation sector (N.I.O.R.D.C 2020). This higher consumption of petroleum products generated higher air pollution in recent years, which has become a major environmental and economic obstacle (Taghvaee and Hajiani 2014). Gasoline consumption in Iran in 2013 was about 68.4 million L per day, while according to unofficial sources, the volume has reached 91.4 million L per day in 2020, and based on the model presented in this article in 2030 it will reach 101.22 million L per day. Therefore, the necessity to substitute gasoline with bioethanol in the transport sector in Iran is quite obvious (Mollahosseini et al. 2017; Kazemi Shariat Panahi et al. 2020).

\section{EXPERIMENTAL}

\section{Methods}

Because bioethanol has not been used as a car fuel in combination with gasoline in Iran, forecasting bioethanol demand is only possible based on estimated values of gasoline demand (Melikoglu 2014). Modeling to predict energy demand in the transport sector is very important and difficult. The difficulty of forecasting is due to the fact that energy demand in this sector is influenced by various and chaotic factors (Geem and Roper 2009; Pao 2009). In addition, unexpected and external events in the economic, social, industrial, political, and environmental sectors cause a change in the predicted trends in the fuel demand model. The use of complex nonlinear modeling systems such as artificial neural networks to predict chaotic time series models such as meteorology (Altan et al. 2021), medical sciences (Ramirez-Carrasco and Molina-Garay 2021), and stock markets (Althelaya et al. 2021) have a long history. The main purpose of employing such models is to minimize the amount of prediction error, one step or several steps ahead. For this purpose, these systems are usually modeled based on differential delay equations, a popular example of which is the widely used Mackey-Glass equation (Li et al. 2012; Han and Wang 2013; da Costa et al. 2021). Therefore, a nonlinear autoregressive neural network was employed to predict gasoline demand based on the Mackey-Glass chaotic time series (Mackey and Glass 1977). The network structure (number of neurons) and other parameters are shown in Table 1. The Mackey-Glass equation used in the neural network is shown in Eq. 1,

$$
\mathrm{d} y(t) / \mathrm{d} t=\left(\left(\alpha y(t-\tau) /\left(1+y^{10}(t-\tau)\right)\right)-\beta y(t)\right.
$$

where $\alpha, \tau$, and $\beta$ are real numbers, and $y(t-\tau)$ represents the value of the variable $y$ at time $(t-\tau)$. Depending on the values of the parameters, this equation displays a range of periodic and chaotic dynamics.

The discretization model of this equation is obtained in Eq. 2,

$$
y(n+1)=y(n)-\beta y(n)+\left(\alpha y(n-\tau) /\left(1+y(n-\tau)^{10}\right)\right)
$$

where it is assumed that $\alpha=0.2, \beta=0.1$, and $\tau=17$ (Althelaya et al. 2021). Note that if $\tau$ $\geq 17$, then there is a chaotic time series (the values of $\alpha$ and $\beta$ are based on Mackey-Glass equation). 
In the Mackey-Glass chaotic time series using artificial neural network, $80 \%$ of the data were randomly selected as training data, $10 \%$ as test data, and $10 \%$ as data for validation. The Levenberg Marquardt method was used for training algorithm, and the MSE (Mean Squared Error) method was used to select the best validation performance of the training algorithm

Table 1. Specifications of Artificial Neural Network

\begin{tabular}{|c|c|c|c|c|}
\hline $\begin{array}{c}\text { Kind of Neural } \\
\text { Network Time Series }\end{array}$ & $\begin{array}{c}\text { Network } \\
\text { Structure (hidden } \\
\text { layer size) }\end{array}$ & $\begin{array}{c}\text { Network } \\
\text { Structure } \\
\text { (number of } \\
\text { neurons) }\end{array}$ & $\begin{array}{c}\text { Input Delay } \\
\text { Vector }\end{array}$ & $\begin{array}{c}\text { Number } \\
\text { of Steps } \\
\text { Ahead }\end{array}$ \\
\hline $\begin{array}{c}\text { Nonlinear } \\
\text { Autoregressive (NAR) }\end{array}$ & 2 & 6 and 3 & $1: 6: 19$ & 18 \\
\hline
\end{tabular}

* Numbers are selected by trial and error with neural network, and best validation performance of the model is evaluated based on MSE (Mean Squared Error).

\section{RESULTS AND DISCUSSION}

\section{Gasoline Demand Forecast by Mackey-Glass Chaotic Time Series using Artificial Neural Network}

Gasoline demand was forecasted by 2030 using MATLAB version 2020b and neural network, based on projected amounts of gasoline, and the required bioethanol amounts were estimated according to different scenarios in Table 2. The outputs of the model show the model was almost appropriate and accurate compared to other models (Fig. 2).

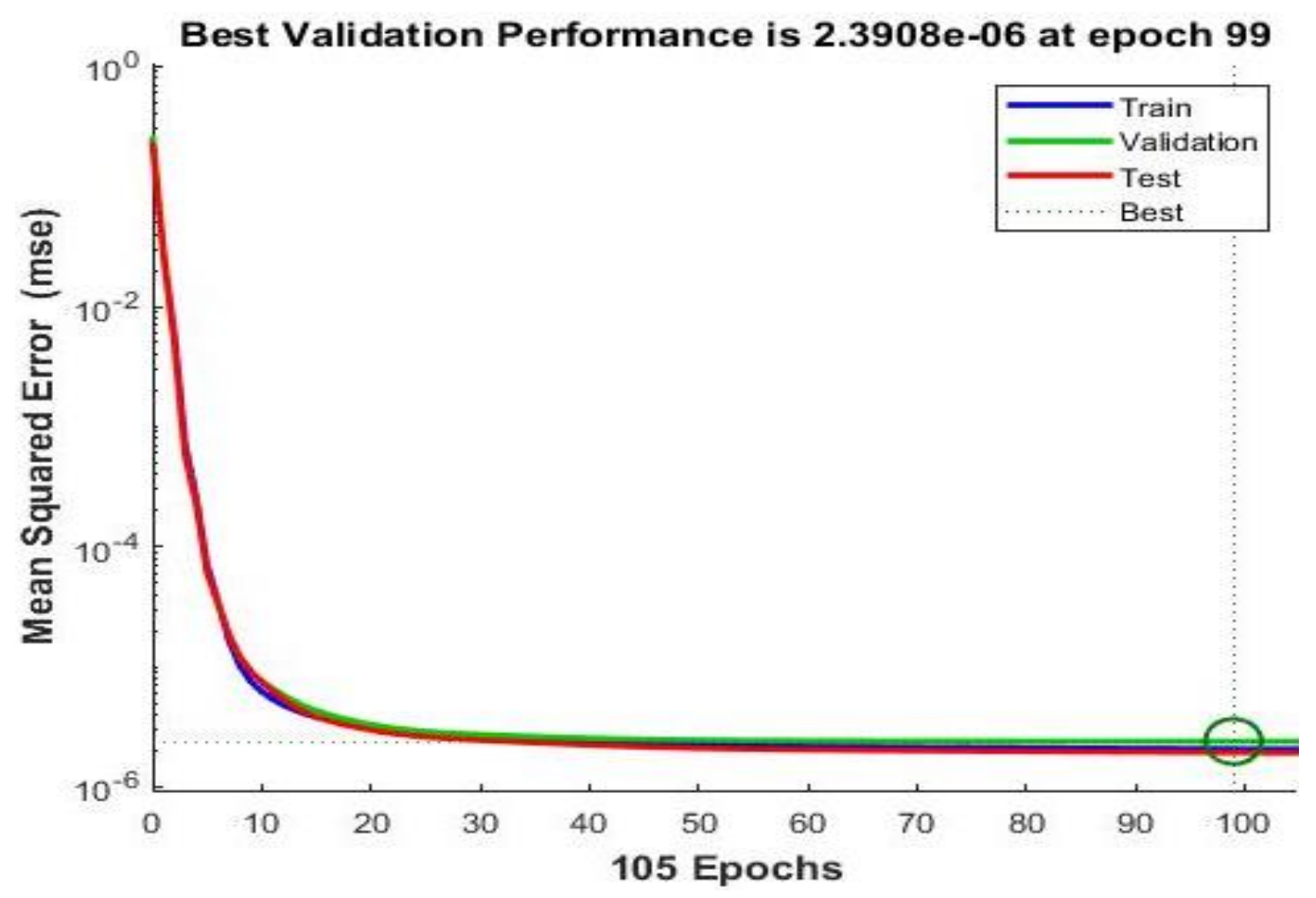

(a) 


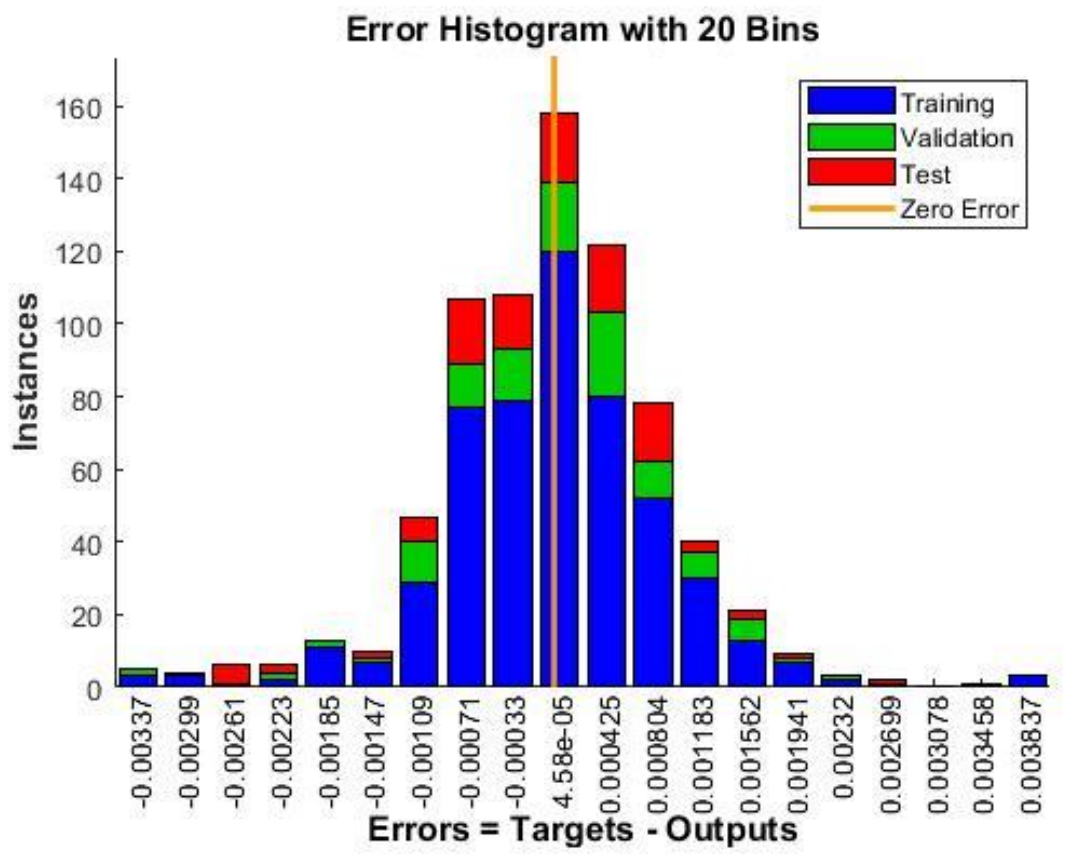

(b)
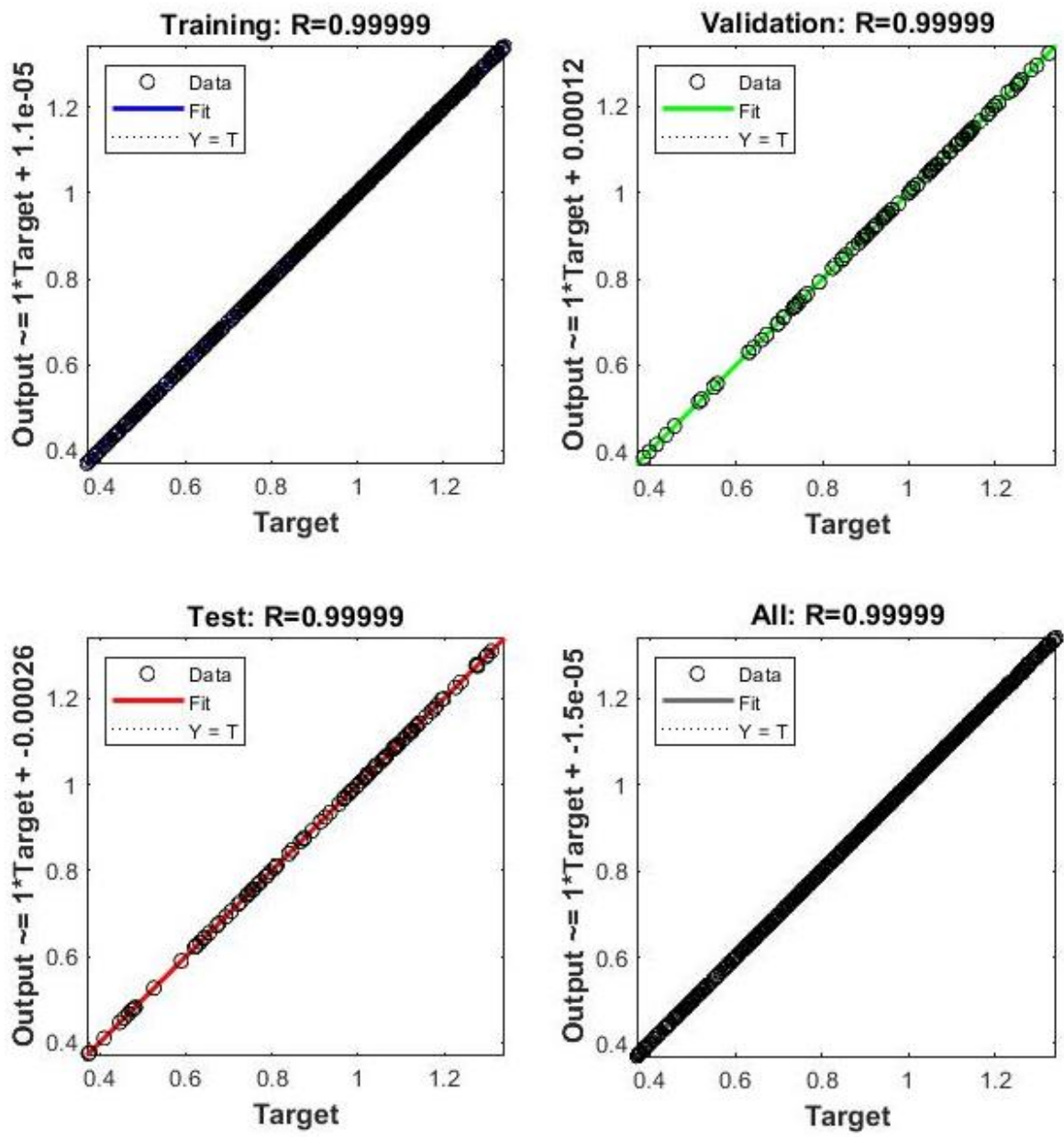

(c) 


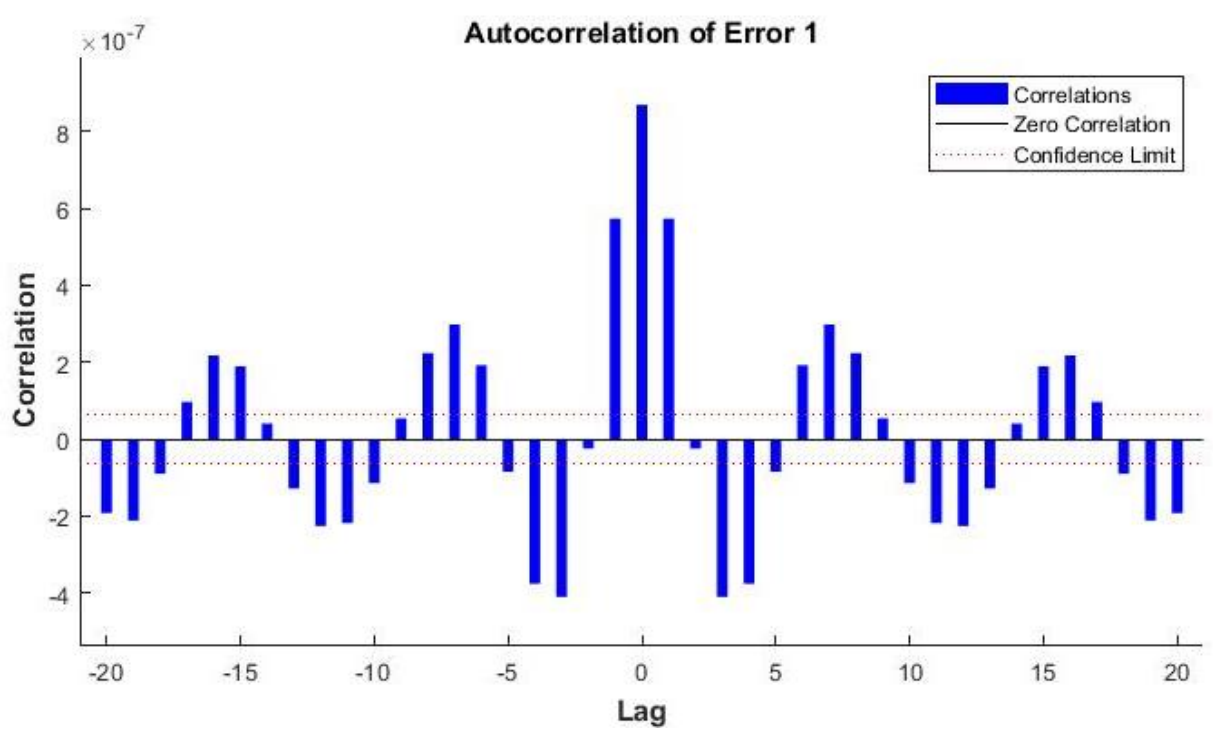

(d)

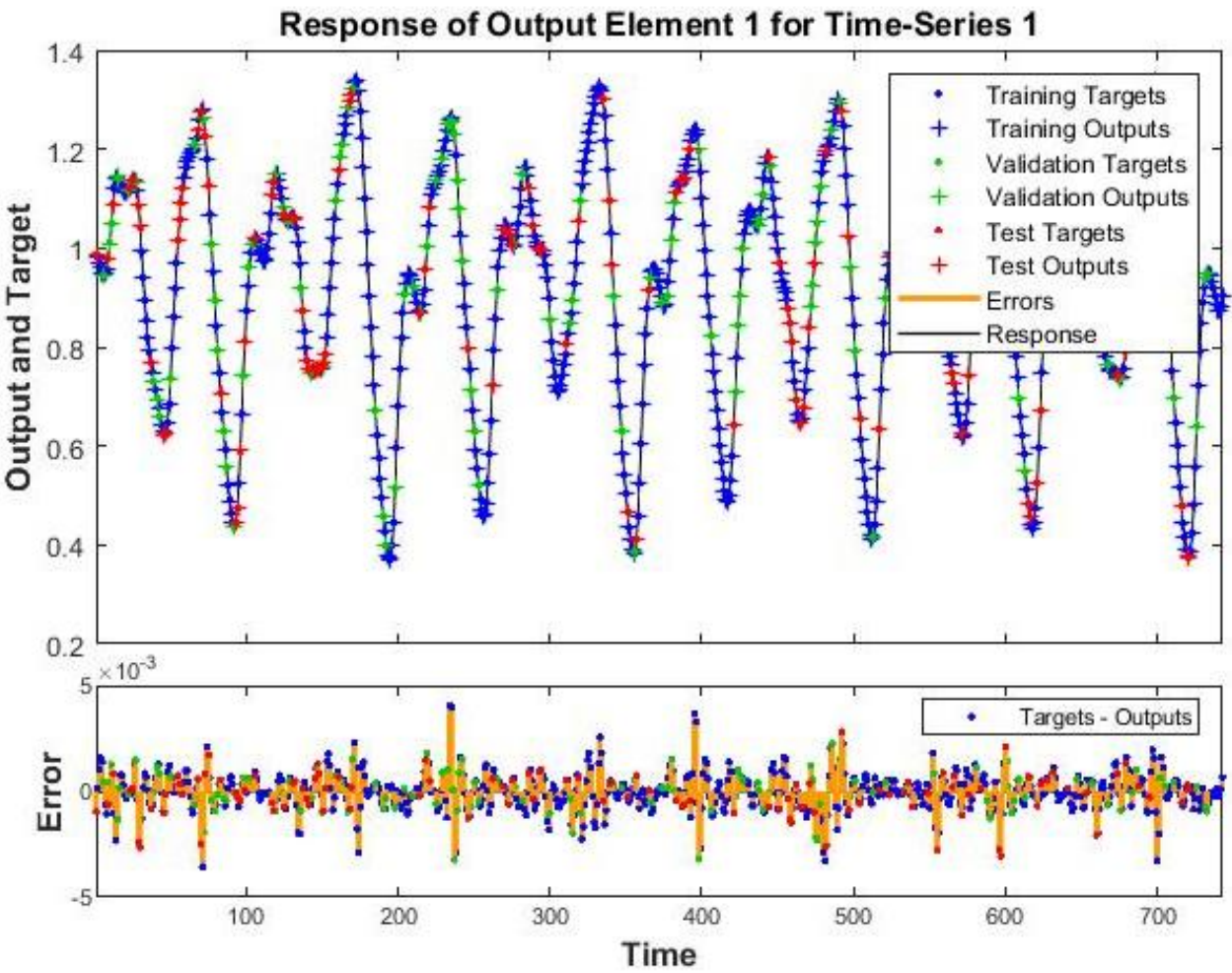

(e)

Fig. 2. (a): In the specified section, the three lines of training, validation, and testing have reached the closest distance to the line of the best (dotted line). Since the repetitions from this stage onwards are without performance improvement, we see the training process stop. The lowest error rate $(2.39080 \mathrm{e}-06)$ occurred in epoch 99, (b): The amount of errors in each category of data is examined, (c): This figure shows the proximity of neural network output data to target data, in 4 separate regression graphs, for training data, test data, validation data, and total data. As shown for all data, the network output data with the target data are on the regression line with very little difference and $99 \%$ correlation coefficient, (d): This diagram shows the similarity of this data with its reverse version, (e): This fitting plot shows the fit of training targets, training outputs, validation targets, validation outputs, test targets, test outputs, errors, and response in the Levenberg-Marquardt method. In the sections where the data fit rate is lower, the error rate in the section below the chart has increased. 
Table 2. Predicted Output Values from the Artificial Neural Network Model Along with the Required Bioethanol Values in Different Scenarios

\begin{tabular}{|c|c|c|c|c|}
\hline Year & $\begin{array}{c}\text { Gasoline } \\
\text { (M. L per day) }\end{array}$ & $\begin{array}{c}\text { Scenario 1 } \\
\text { Bioethanol (E10) (M. } \\
\text { L per day) }\end{array}$ & $\begin{array}{c}\text { Scenario 2 } \\
\text { Bioethanol (E15) } \\
\text { (M. L per day) }\end{array}$ & $\begin{array}{c}\text { Scenario 3 } \\
\text { Bioethanol (E25) } \\
\text { (M. L per day) }\end{array}$ \\
\hline 2020 & 91.4 & 9.14 & 13.71 & 22.85 \\
\hline 2021 & 91.93 & 9.19 & 13.79 & 22.98 \\
\hline 2022 & 92.43 & 9.24 & 13.87 & 23.11 \\
\hline 2023 & 93.05 & 9.3 & 13.96 & 23.26 \\
\hline 2024 & 93.84 & 9.38 & 14.08 & 23.46 \\
\hline 2025 & 94.84 & 9.48 & 14.23 & 23.71 \\
\hline 2026 & 96.03 & 9.6 & 14.4 & 24.01 \\
\hline 2027 & 97.41 & 9.74 & 14.61 & 24.35 \\
\hline 2028 & 98.95 & 9.9 & 14.84 & 24.74 \\
\hline 2029 & 100.33 & 10.03 & 15.05 & 25.08 \\
\hline 2030 & 101.22 & 10.12 & 15.18 & 25.31 \\
\hline
\end{tabular}

Based on the data predicted by the model, with the continuation of the trend of increasing gasoline consumption, it is estimated that the problems of air pollution will intensify in the coming years. In addition, if US sanctions against Iran are lifted, and if the GDP returns to the trend which was before 2018, the consumption of gasoline and other petroleum products will increase and this problem will intensify. One of the other reasons for this increase is that the price of gasoline is low due to the payment of large government subsidies to this sector. There is no policy or strategy to set goals in fuel pricing because Iran's economy is highly dependent on fuel prices, which leads to doubts about the correct pricing. In addition, the number of cars has increased significantly, and the technologies of the vehicles produced are too old, making the average fuel consumption of most newly produced vehicles higher than what is normal in other parts of the world.

Agricultural residues, especially lignocellulosic products, due to their suitable cellulose and hemicellulose content as the main substance of sugar production in the ethanol conversion chain, are considered as a suitable source for biofuel production (Eckert et al. 2018). Various studies have examined the possibility of using municipal waste, agricultural residues, especially lignocellulosic sources such as bagasse, industrial waste (such as pulp and paper and food industries wastes) in Iran, and the results show that the use of second-generation bioethanol production in Iran is economically and technically feasible due to its abundance and low cost of feedstock ( Ghobadian 2012; Madadi et al. 2017; Kazemi Shariat Panahi et al. 2019; Kazemi Shariat Panahi et al. 2020; Ahmadi et al. 2020; Ahranjani et al. 2020).

It is estimated that 17 to $30 \%$ (in some cases up to $50 \%$ ) of Iran's total crop production will be converted into agricultural waste. This percentage is not the same for all crops, for example in the case of products such as wheat, approximately $50 \%$ and according to the FAO, approximately $30 \%$ of total rice production is also lost as waste. If one considers the annual production of wheat in Iran to be about 15 million tons, wheat waste can be used to produce 3 billion L of bioethanol per year. Also, it is estimated that about 1.05 million tons of rice waste is produced annually, of which about 400 million $\mathrm{L}$ of bioethanol can be produced (Mollahosseini et al. 2017). Bagasse is also one of the most abundant agricultural residues in the world, which has recently been considered as a source of second-generation bioethanol. The production potential of bioethanol from sugarcane and sugar beet has been reported to be 70 and 110 (L per hectare) per year, respectively 
(Kumar NV et al. 2006), and the approximate production volume of sugar beet and sugarcane molasses in Iran is about 500 million L, which can be given special attention in future planning and policies (Saadati and Hosseininezhad 2019; Adewuyi 2020). The total amount of agricultural waste in Iran in 2012 was estimated at 17.86 million tons, which be used to generate 5 billion L of bioethanol for the hypothetical scenario E10 by 2026 (Ghobadian 2012). Evaluations in recent articles show that the total amount of agricultural waste is estimated at 24.3 million tons, of which 6,542 million $\mathrm{m}^{3}$ of biogas, 2,443 million L of bioethanol, and 2,082 million $\mathrm{m}^{3}$ of biohydrogen can be produced (Safieddin Ardebili 2020). Results in other research have shown that Iran can produce more than 4.91 billion L of bioethanol per year employing agricultural waste (Ahmadi et al. 2020).

In general, different volumes of suitable primary sources for biofuel production in Iran have been reported (Ahmadi et al. 2020). In this study, it is attempted to improve the estimated demand and production potential of bioethanol by using the latest and reliable information in a suitable model.

\section{Potentials to Produce Second Generation Bioethanol}

Different and contradictory information on agricultural resources and wastes has been published in various references. Therefore, at the first step, the most up-to-date statistics of all agricultural products in the last 40 years have been collected from reliable sources. Among these crops, 6 energy crops were selected for bioethanol production, which were more suitable in terms of production volume and planting rate in large areas (Fig. 3). Based on these data, it has been determined that the amount of agricultural production and these six energy crops are increasing (Fig. 4).

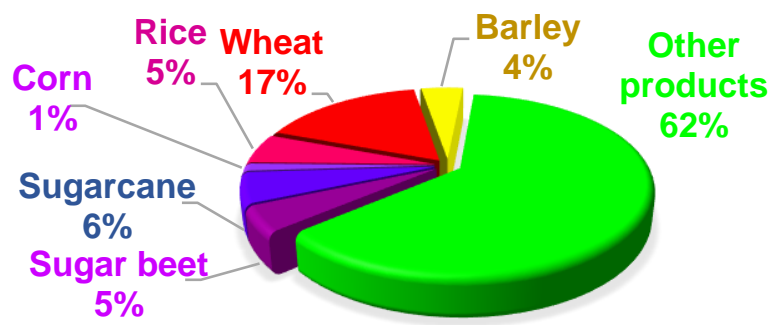

Fig. 3. Percentage of energy crops from total agricultural products produced in 2019 in Iran (Ministry of Agriculture - Jahad 2021)

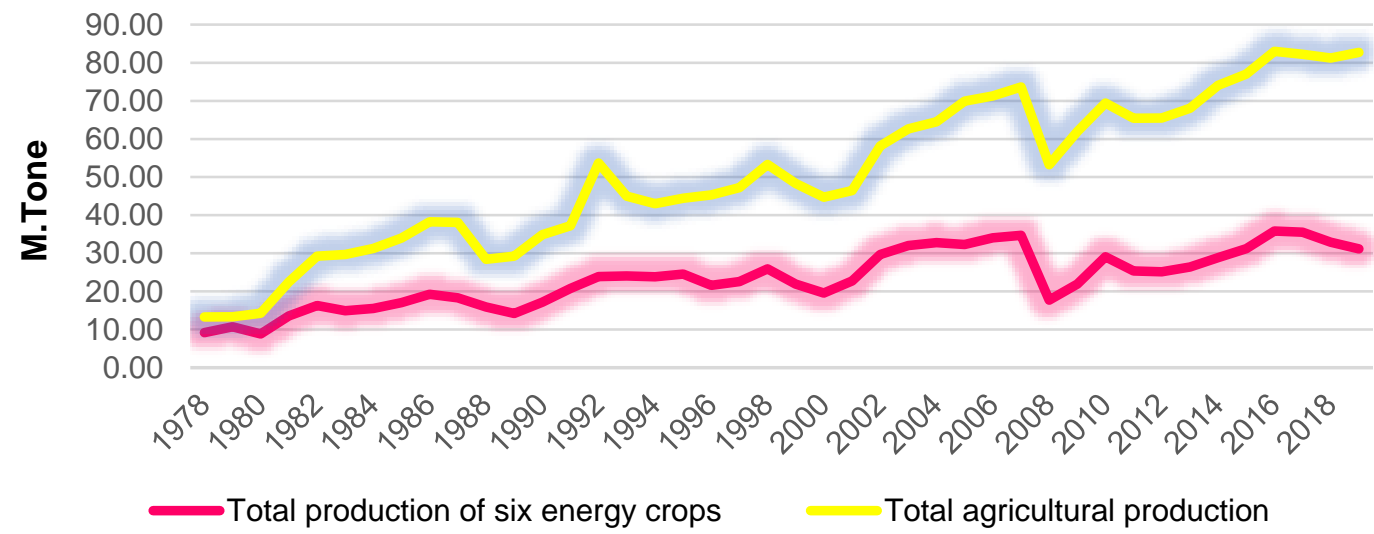

Fig. 4. Increasing trend of agricultural production in Iran during the last 40 years (Ministry of Agriculture - Jahad 2021) 
Table 4. Potential of Bioethanol Production from Agricultural Waste of Six Selected Energy Crops

\begin{tabular}{|c|c|c|c|c|c|}
\hline Product & $\begin{array}{c}\text { Total } \\
\text { Production } \\
\text { (M.Tons) }\end{array}$ & $\begin{array}{c}\text { Percentage } \\
\text { of Waste }\end{array}$ & $\begin{array}{c}\text { Amount } \\
\text { of Waste } \\
\text { (M.Tons) }\end{array}$ & $\begin{array}{c}\text { Conversion } \\
\text { Coefficient of } \\
\text { Product Waste to } \\
\text { Bioethanol (L per } \\
\text { ton) }\end{array}$ & $\begin{array}{c}\text { Volume of } \\
\text { Bioethanol (M. } \\
\text { L per year) }\end{array}$ \\
\hline Wheat & 13.715 & $50 \%$ & 6.858 & 400 & 2743.2 \\
\hline Sugarcane & 4.568 & $35 \%$ & 1.599 & 360 & 575.74 \\
\hline Sugar beet & 3.833 & $30 \%$ & 1.150 & $135-300$ & 345 \\
\hline Barley & 3.514 & $30 \%$ & 1.054 & 300 & 316.2 \\
\hline Rough Rice & 4.422 & $30 \%$ & 1.327 & 400 & 530.8 \\
\hline Corn & 1.101 & $30 \%$ & 0.330 & 350 & 115.5 \\
\hline $\begin{array}{c}\text { Sum of } \\
\text { selected } \\
\text { energy crops }\end{array}$ & 31.155 & & 12.318 & - & 4626.44 \\
\hline Others crops & 51.575 & $30 \%$ & 15.473 & 100 & 5157.5 \\
\hline Total & 82.73 & & 27.791 & - & 9783.94 \\
\hline
\end{tabular}

According to the latest official statistics published by the Ministry of Agriculture Jahad of Iran (which covers information until 2019), the total production of Iran's agricultural products is about 82.730 million tons, and at least $30 \%$ to $50 \%$ is wasted, which amounts to estimated 27.79 million tons (Ministry of Agriculture - Jahad 2021). With an average conversion factor of 100 to $300 \mathrm{~L}$ per ton, then about 9.78 billion L of bioethanol can be produced annually (about 26.81 million L per day). This means that if the current potential of all agricultural wastes in Iran is properly planned and used, 26.81 million L of bioethanol can be produced daily and it will fulfill the needed bioethanol for gasoline vehicles. This will provide the required bioethanol in all three scenarios (Table 5) up to the next 10 years and there will be no need to cultivate and produce more energy crops. According to the results obtained, which are summarized in Tables 4 and 5, as it is clear that the highest amount of demand will occur in 2030 when gasoline consumption will reach up to 101.12 million $\mathrm{L}$ per day.

Table 5. Bioethanol Demand for 3 Scenarios by 2030

\begin{tabular}{|c|c|c|c|c|}
\hline Year & $\begin{array}{c}\text { Gasoline Demand } \\
\text { forecast (M. L per } \\
\text { day) }\end{array}$ & $\begin{array}{c}\text { Bioethanol } \\
\text { Demand for E10 } \\
\text { (M. L per day) }\end{array}$ & $\begin{array}{c}\text { Bioethanol } \\
\text { Demand for E15 } \\
\text { (M. L per day) }\end{array}$ & $\begin{array}{c}\text { Bioethanol } \\
\text { Demand for E25 } \\
\text { (M. L per day) }\end{array}$ \\
\hline 2020 & 91.40 & 9.14 & 13.71 & 22.85 \\
\hline 2030 & 101.22 & 10.12 & 15.18 & 25.31 \\
\hline
\end{tabular}

Therefore, policymakers and government officials must prepare themselves to face this volume of demand and the environmental and economic damages caused by this volume of gasoline consumption. In this study, three scenarios are proposed. According to the first scenario (E10), it is necessary to combine gasoline with $10 \%$ bioethanol. Therefore, a maximum volume of 10.12 million $\mathrm{L}$ of bioethanol per day will be needed by 2030. The second and third scenarios (E15) and (E25) will require 15.18 and 25.31 million L of bioethanol per day by 2030, respectively. In the first steps, it seems difficult to collect all agricultural waste and convert it into bioethanol. A closer look at Table 4 reveals that six energy crops (wheat, corn, sugarcane and sugar beet, rough rice, and barley) alone 
produce 4626 million L of bioethanol per year, which is almost equal to other agricultural products that produce 5158 million L of bioethanol per year. This amount of bioethanol will be enough even by 2030 if the goal is to meet the country's bioethanol needs for the first scenario $(\mathrm{E} 10=10.12$ million $\mathrm{L})$ at a lower cost and with a very short planning period.

In Iran and other parts of the world, the use of bioethanol as a vehicle fuel is highly dependent on government support, and the forecast of its demand is not subject to gasoline consumption factors (Chanthawong et al. 2020; D'Adamo et al. 2020; Haputta et al. 2020). Because the consumption of biofuels is not economically competitive with fossil fuels due to the high costs of its production, it requires investment, government support in the biofuels sector, the elimination of government subsidies from gasoline, and the approval of consumption taxes (Chanthawong et al. 2020). However, the output of the model, according to its input information, correctly predicts a slower upward trend for the years 2020 to 2030 than for the period 2010 to 2020 (This decrease in demand is due to the imposition of maximum sanctions on Iran's economy and automobile industry, which reduces domestic car production, as well as a sharp decline in Iran's GDP, is fully justified). Of course, the COVID-19 pandemic will also be very effective in reducing demand and will bring our forecast results very close to real values in the future. Along with the sustainable and safe development of green fuel, which is well calculated and evaluated, it will be clear how vital and necessary it is to invest in biofuel industries such as bioethanol, even for an oil-rich country like Iran.

\section{CONCLUSIONS}

1. According to the latest official and updated statistics in this research, more than a quarter of fossil energy is consumed in the transportation sector in Iran and this sector, especially gasoline vehicles, is one of the most important producers of greenhouse gases. Therefore, the policy of using biofuels and reducing the consumption of fossil fuels needs to focus on this sector. This goal can only be achieved by enforcing government protection laws, providing government subsidies on biofuels, imposing a tax on fossil fuels, and investing in biofuels research and development to reduce the cost of biofuels.

2. This study predicted the exact amounts of bioethanol demand for gasoline vehicles by Mackey-Glass chaotic time series using Artificial Neural Network until 2030. Based on this, it is predicted that the increasing trend of fuel demand will gradually continue until 2030 and the highest demand will reach 101.22 million L per day in 2030.

3. This study proposed three scenarios (E10, E15, and E25) with the maximum demand for bioethanol as 10.12, 15.18, and 25.31 million L per day, respectively, required by 2030.

4. If properly planned and the current potential of all agricultural wastes in Iran is used, 26.81 million L of bioethanol can be produced daily, and if the goal is to use only the potential of six energy crops (wheat, corn, sugarcane and sugar beet, rough rice, and barley) alone, 12.68 million L per day of bioethanol can be produced.

5. Therefore, the current potential of all agricultural wastes will provide bioethanol in all three scenarios and there will be no need to cultivate and produce more energy crops. If the goal is to meet the country's bioethanol needs for the first scenario (E10 $=10.12$ million L) at a lower cost and with a very short planning period, the amount of 
bioethanol from six energy crops will be enough even by 2030. Of course two issues ought to be considered in this respect. Does the cultivation of the selected crops continue, considering the climate change and possible drought in middle east and also the advances in crop harvesting and processing technologies reduces the amount of waste currently generated? It should be pointed out that water management and advance irrigation techniques will increase the total cultivation areas of the crops in Iran.

\section{REFERENCES CITED}

Adewuyi, A. (2020). "Challenges and prospects of renewable energy in Nigeria: A case of bioethanol and biodiesel production," Energy Reports 6, 77-88. DOI:

10.1016/j.egyr.2019.12.002

Ahmadi, A., Esmaeilion, F., Esmaeilion, A., Ehyaei, M. A., and Silveira, J. L. (2020). "Benefits and limitations of waste-to-energy conversion in Iran," Renewable Energy Research and Application 1(1), 27-45. DOI: 10.22044/RERA.2019.8666.1007

Ahorsu, R., Medina, F., and Constantí, M. (2018). "Significance and challenges of biomass as a suitable feedstock for bioenergy and biochemical production: A review," Energies 11(12), 3366. DOI: 10.3390/en11123366

Ahranjani, P. M., Ghaderi, S. F., Azadeh, A., and Babazadeh, R. (2020). "Robust design of a sustainable and resilient bioethanol supply chain under operational and disruption risks," Clean Technologies and Environmental Policy 22(1), 119-151. DOI: 10.1007/s10098-019-01773-2

Air Quality Control Company (2021). "Air pollution - Tehran Municipality," (http://airnow.tehran.ir), Accessed 2 February 2021.

Alalwan, H. A., Alminshid, A. H., and Aljaafari, H. A. S. (2019). "Promising evolution of biofuel generations. Subject review," Renewable Energy Focus 28, 127-139. DOI: 10.1016/j.ref.2018.12.006

Altan, A., Karasu, S., and Zio, E. (2021). "A new hybrid model for wind speed forecasting combining long short-term memory neural network, decomposition methods and grey wolf optimizer," Applied Soft Computing 100, 106996. DOI: 10.1016/j.asoc.2020.106996

Althelaya, K. A., Mohammed, S. A., and El-Alfy, E. S. M. (2021). "Combining deep learning and multiresolution analysis for stock market forecasting," IEEE Access, 9, 13099-13111. DOI: 10.1109/ACCESS.2021.3051872

Bonenkamp, T. B., Middelburg, L. M., Hosli, M. O., and Wolffenbuttel, R. F. (2020). "From bioethanol containing fuels towards a fuel economy that includes methanol derived from renewable sources and the impact on European Union decision-making on transition pathways," Renewable and Sustainable Energy Reviews 120, 109667. DOI: 10.1016/j.rser.2019.109667

Chanthawong, A., Dhakal, S., Kuwornu, J. K. M., and Farooq, M. K. (2020). "Impact of subsidy and taxation related to biofuels policies on the economy of Thailand: A dynamic CGE modelling approach," Waste and Biomass Valorization 11(3), 909-929. DOI: $10.1007 / \mathrm{s} 12649-018-0417-4$

Cheah, W. Y., Sankaran, R., Show, P. L., Tg. Ibrahim, T. N. B., Chew, K. W., Culaba, A., and Chang, J.-S. (2020). "Pretreatment methods for lignocellulosic biofuels production: Current advances, challenges and future prospects," Biofuel Research 
Journal 7(1), 1115-1127. DOI: 10.18331/brj2020.7.1.4

Cohen, A. J., Brauer, M., Burnett, R., Anderson, H. R., Frostad, J., Estep, K., Balakrishnan, K., Brunekreef, B., Dandona, L., Dandona, R., Feigin, V., Freedman, G., Hubbell, B., Jobling, A., Kan, H., Knibbs, L., Liu, Y., Martin, R., Morawska, L., Pope, C. A., Shin, H., Straif, K., Shaddick, G., Thomas, M., van Dingenen, R., van Donkelaar, A., Vos, T., Murray, C. J. L., and Forouzanfar, M. H. (2017). "Estimates and 25-year trends of the global burden of disease attributable to ambient air pollution: An analysis of data from the Global Burden of Diseases Study 2015," The Lancet 389(10082), 1907-1918. DOI: 10.1016/S0140-6736(17)30505-6

da Costa, M. N., Attux, R., Cichocki, A., and Romano, J. M. T. (2021). "Tensor-train networks for learning predictive modeling of multidimensional data," Preprint Submitted to Elsevier. arXiv: 2101.09184v3[cs:LG]. 30 Mar 2021.

D’Adamo, I., Falcone, P. M., Gastaldi, M., and Morone, P. (2020). "RES-T trajectories and an integrated SWOT-AHP analysis for biomethane. Policy implications to support a green revolution in European transport," Energy Policy 138, article no. 111220. DOI: 10.1016/j.enpol.2019.111220

Department of Energy \& Climate Change. (2012). CCS Roadmap (URN 12D/016), Crown, London.

Eckert, C. T., Frigo, E. P., Albrecht, L. P., Albrecht, A. J. P., Christ, D., Santos, W. G., Berkembrock, E., and Egewarth, V. A. (2018). "Maize ethanol production in Brazil: Characteristics and perspectives," Renewable and Sustainable Energy Reviews 82, 3907-3912. DOI: 10.1016/j.rser.2017.10.082

Environment and Climate Change Canada. (2020). "Canadian environmental sustainability indicators: Global greenhouse gas emissions," (https://www.canada.ca/en/environment-climate-change/services/environmentalindicators/global-greenhouse-gas-emissions.html), Accessed 5 September 2020

Farine, D. R., O'Connell, D. A., Raison, R. J., May, B. M., O’Connor, M. H., Crawford, D. F., Herr, A., Taylor, J. A., Jovanovic, T., Campbell, P. K., Dunlop, M. I. A., Rodriguez, L. C., Poole, M. L., Braid, A. L., and Kriticos, D. (2012). "An assessment of biomass for bioelectricity and biofuel, and for greenhouse gas emission reduction in Australia," GCB Bioenergy 4(2), 148-175. DOI: 10.1111/j.17571707.2011.01115.x

Field, J. L., Evans, S. G., Marx, E., Easter, M., Adler, P. R., Dinh, T., Willson, B., and Paustian, K. (2018). "High-resolution techno-ecological modelling of a bioenergy landscape to identify climate mitigation opportunities in cellulosic ethanol production," Nature Energy 3(3), 211-219. DOI: 10.1038/s41560-018-0088-1

Geem, Z. W. and Roper, W. E. (2009). "Energy demand estimation of South Korea using artificial neural network," Energy Policy 37(10), 4049-4054. DOI:

10.1016/j.enpol.2009.04.049

Gheorghe, I. F., and Ion, B. (2012). "The effects of air pollutants on vegetation and the role of vegetation in reducing rtmospheric pollution," in: Textbook of The Impact of Air Pollution on Health, Economy, Environment and Agricultural Sources, M. K. Khallaf, (ed.), InTech, Rijeka, Croatia. DOI: 10.5772/1000, pp. 239-280.

Ghobadian, B. (2012). "Liquid biofuels potential and outlook in Iran," Renewable and Sustainable Energy Reviews 16(7), 4379-4384. DOI: 10.1016/j.rser.2012.05.013

Gilani, H. and Sahebi, H. (2020). "A multi-objective robust optimization model to design sustainable sugarcane-to-biofuel supply network: The case of study," Biomass Conversion and Biorefinery. DOI: 10.1007/s13399-020-00639-8 
Hahad, O., Lelieveld, J., Birklein, F., Lieb, K., Daiber, A., and Münzel, T. (2020). "Ambient air pollution increases the risk of cerebrovascular and neuropsychiatric disorders through induction of inflammation and oxidative stress," International Journal of Molecular Sciences 21(12), 4306. DOI: 10.3390/ijms21124306

Hamje, H. D. C., Hass, H., Lonza, L., Maas, H., Reid, A., Rose, K. D., Venderbosch, T. (2014). EU Renewable Energy Targets in 2020 : Revised Analysis of Scenarios for Transport Fuels (EUR 26581 EN), Joint Research Centre, Publications Office of the European Union, Luxembourg.

Han, M. and Wang, X. (2013). "Robust neural predictor for noisy chaotic time series prediction," Proceedings of the 2013 International Joint Conference on Neural Networks, Dallas, TX. DOI: 10.1109/IJCNN.2013.6706996

Haputta, P., Puttanapong, N., Silalertruksa, T., Bangviwat, A., Prapaspongsa, T., and Gheewala, S. H. (2020). "Sustainability analysis of bioethanol promotion in Thailand using a cost-benefit approach," Journal of Cleaner Production 251, 119756. DOI: 10.1016/j.jclepro.2019.119756

Hassan, S. S., Williams, G. A., and Jaiswal, A. K. (2018). "Emerging technologies for the pretreatment of lignocellulosic biomass," Bioresource Technology 262, 310-318. DOI: 10.1016/j.biortech.2018.04.099

Heger, M., and Sarraf, M. (2018). Air Pollution in Tehran: Health Costs, Sources, and Policies (Environment and Natural Resources Global Practice Discussion Paper No. 6), World Bank, Washington, D.C.

Ho, A. F. W., Zheng, H., Cheong, K. H., En, W. L., Pek, P. P., Zhao, X., Morgan, G. G., Earnest, A., Tan, B. Y. Q., Ng, Y. Y., Foo, L. L., Ong, M.E. H. (2020). “The relationship between air pollution and all-cause mortality in Singapore," Atmosphere 11(1), 9. DOI: 10.3390/atmos11010009

IEA. (2020). "International Energy Agency," (https://www.iea.org/data-andstatistics/charts), Accessed 5 March 2021

IQAir. (2019). 2019 World Air Quality Report, Greenpeace, Amsterdam, Netherlands.

Kazemi Shariat Panahi, H., Dehhaghi, M., Kinder, J., and Ezeji, T. (2019). "A review on green liquid fuels for the transportation sector: A prospect of microbial solutions to climate change," Biofuel Research Journal 6(3), 995-1024. DOI: 10.18331/BRJ2019.6.3.2

Kazemi Shariat Panahi, H., Dehhaghi, M., Aghbashlo, M., Karimi, K., and Tabatabaei, M. (2020). "Conversion of residues from agro-food industry into bioethanol in Iran: An under-valued biofuel additive to phase out MTBE in gasoline," Renewable Energy 145, 699-710. DOI: 10.1016/j.renene.2019.06.081

Li, D., Han, M., and Wang, J. (2012). "Chaotic time series prediction based on a novel robust echo state network," IEEE Transactions on Neural Networks and Learning Systems 23(5), 787-799. DOI: 10.1109/TNNLS.2012.2188414

Linoj, K. N. V., Dhavala, P., Goswami, A., and Maithel, S. (2006). "Liquid biofuels in South Asia: Resources and Technologies," Asian Biotechnology and Development Review 8(2), 31-49. Research and Information System (RIS), www.ris.org.in/abdr.html.

Mackey, M. C., and Glass, L. (1977). "Fatty acids and their prostaglandin derivatives: Inhibitors of proliferation in aortic smooth muscle cells," Science 197, 287-289.

Madadi, M., Hosieni, S. M., Khalili, I., and Abbas, A. (2017). "A review on renewable energy resources in Iran," in: $3^{\text {rd }}$ International Conference on Sustainable Development, Strategies and Challenges With a Focus on Agriculture, Natural 
Resources, Environment and Tourism, Tabriz, Iran, pp. 7-9.

Melikoglu, M. (2014). "Demand forecast for road transportation fuels including gasoline, diesel, LPG, bioethanol and biodiesel for Turkey between 2013 and 2023," Renewable Energy 64, 164-171. DOI: 10.1016/j.renene.2013.11.009

Mikhelkis, L., and Govindarajan, V. (2020). "Techno-economic and partial environmental analysis of carbon capture and storage (CCS) and carbon capture, utilization, and storage (CCU/S): Case study from proposed waste-fed district-heating incinerator in Sweden," Sustainability 12(15), 5922. DOI: 10.3390/su12155922

Ministry of Agriculture - Jahad. (2021). "Information and Statistics Department of Agricultural Ministry of Iran," (http://amar.maj.ir) (In Persian)'

Mollahosseini, A., Hosseini, S. A., Jabbari, M., Figoli, A., and Rahimpour, A. (2017). "Renewable energy management and market in Iran: A holistic review on current state and future demands," Renewable and Sustainable Energy Reviews 80, 774-788. DOI: 10.1016/j.rser.2017.05.236

Mostafaeipour, A., Sedaghat, A., Hedayatpour, M., and Jahangiri, M. (2020). "Location planning for production of bioethanol fuel from agricultural residues in the south of Caspian Sea," Environmental Development 33, 100500. DOI: 10.1016/j.envdev.2020.100500

N.I.O.R.D.C. (2020). "National Iranian oil refining and distribution company" (https://niordc.ir/index.aspx?fkeyid=\&siteid=78\&pageid=3060), Accessed 5 February 2021

Neves, R. C., Klein, B. C., da Silva, R. J., Rezende, M. C. A. F., Funke, A., OlivarezGómez, E., Bonomi, A., and Maciel-Filho, R. (2020). "A vision on biomass-to-liquids (BTL) thermochemical routes in integrated sugarcane biorefineries for biojet fuel production," Renewable and Sustainable Energy Reviews 119, 109607. DOI: 10.1016/j.rser.2019.109607

Nikkhah, A., El Haj Assad, M., Rosentrater, K. A., Ghnimi, S., and Van Haute, S. (2020). "Comparative review of three approaches to biofuel production from energy crops as feedstock in a developing country," Bioresource Technology Reports 10, 100412. DOI: 10.1016/j.biteb.2020.100412

Pao, H. T. (2009). "Forecasting energy consumption in Taiwan using hybrid nonlinear models," Energy 34(10), 1438-1446. DOI: 10.1016/j.energy.2009.04.026

Rabbani, M., Momen, S., Akbarian-Saravi, N., Farrokhi-Asl, H., and Ghelichi, Z. (2020). "Optimal design for sustainable bioethanol supply chain considering the bioethanol production strategies: A case study," Computers \& Chemical Engineering 134, 106720. DOI: 10.1016/j.compchemeng.2019.106720

Ramirez-Carrasco, C. and Molina-Garay, J. (2021). "Existence and approximation of traveling wavefronts for the diffusive Mackey-Glass equation," Australian Journal of Mathematical Analysis and Applications 18(1), 1-12.

REN21. (2020). Renewables 2020 Global Status Report, REN21 Secretariat, Paris, France.

Saadati, M. and Hosseininezhad, S. J. (2019). "Designing a hub location model in a bagasse-based bioethanol supply chain network in Iran (case study: Iran sugar industry)," Biomass and Bioenergy 122, 238-256. DOI:

10.1016/j.biombioe.2019.01.013

Safarian, S. and Unnthorsson, R. (2018). "An assessment of the sustainability of lignocellulosic bioethanol production from wastes in Iceland," Energies 11(6), 1493. DOI: $10.3390 /$ en11061493 
Safieddin Ardebili, S. M. (2020). "Green electricity generation potential from biogas produced by anaerobic digestion of farm animal waste and agriculture residues in Iran," Renewable Energy 154, 29-37. DOI: 10.1016/j.renene.2020.02.102

Sarkar, N., Ghosh, S. K., Bannerjee, S., and Aikat, K. (2012). "Bioethanol production from agricultural wastes: An overview," Renewable Energy 37(1), 19-27. DOI: 10.1016/j.renene.2011.06.045

Szulecka, J. (2019). "Towards sustainable wood-based energy: Evaluation and strategies for mainstreaming sustainability in the sector," Sustainability 11(2), 493. DOI: $10.3390 /$ su 11020493

Taghvaee, V. M. and Hajiani, P. (2014). "Price and income elasticities of gasoline demand in Iran: Using static, ECM, and dynamic models in short, intermediate, and long run," Modern Economy 5(9), 939-950. DOI: 10.4236/me.2014.59087

Tursi, A. (2019). "A review on biomass: Importance, chemistry, classification, and conversion," Biofuel Research Journal 6(2), 962-979. DOI: 10.18331/BRJ2019.6.2.3

World Bank Group. (2020). "World bank open data," (https://data.worldbank.org), Accessed 7 February 2021

World Bank Group, and IHME. (2016). "The Cost of Air Pollution: Strengthening the Economic Case for Action," (The World Bank and Institute for Health Metrics and Evaluation University of Washington, Seattle), (http://www.tandfonline.com/doi/abs/10.1080/000368497326688\#.Va9xXPnQjVI), Accessed 5 September 2020

World Energy Council (2016). World Energy Resources 2016, London.

Worldometers. (2021). "Worldometers," (https://www.worldometers.info), Accessed 8 March 2021

Yanagi, K. and Nakamura, A. (2020). "Towards a low/zero carbon society for the AsiaPacific region: Policy and legal development for carbon capture and storage (CCS) in Japan," in: Sustainability and Law, V. Mauerhofer, D. Rupo, L. Tarquinio (eds.), Springer, Cham, Switzerland, pp. 585-605.

Article submitted: April 3, 2021; Peer review completed: April 25, 2021; Revised version received and accepted: May 3, 2021; Published: May 11, 2021.

DOI: $10.15376 /$ biores.16.3.4798-4813 